\title{
Occupational Radiation Protection in Interventional Radiology: A Joint Guideline of the Cardiovascular and Interventional Radiology Society of Europe and the Society of Interventional Radiology
}

\author{
Donald L. Miller • Eliseo Vañó • Gabriel Bartal • Stephen Balter • \\ Robert Dixon - Renato Padovani - Beth Schueler • John F. Cardella • \\ Thierry de Baère
}

Received: 4 November 2009/Accepted: 4 November 2009/Published online: 18 December 2009

(C) Springer Science+Business Media, LLC and the Cardiovascular and Interventional Radiological Society of Europe (CIRSE) 2009

\section{Preamble}

The members of the Cardiovascular and Interventional Society of Europe (CIRSE) Standards of Practice committee and the Society of Interventional Radiology (SIR) Safety and Health Committee represent experts in a broad spectrum of interventional procedures from both the private and the academic sectors of medicine. Generally, these committee members dedicate the vast majority of their professional time to performing interventional procedures; as such, they represent a valid broad expert constituency of the subject matter under consideration.

Technical documents specifying the exact consensus and literature review methodologies as well as the institutional affiliations and professional credentials of the authors of this document are available upon request from SIR, 3975 Fair Ridge Drive, Suite 400 North, Fairfax, VA 22033, USA.

\footnotetext{
D. L. Miller $(\varangle)$

Department of Radiology, Uniformed Services University, Bethesda, MD, USA

e-mail: Donald.Miller@med.navy.mil

E. Vañó

Radiology Department, San Carlos University Hospital,

Complutense University, Madrid, Spain

G. Bartal

Department of Diagnostic and Interventional Radiology,

Meir Medical Center, Kfar Saba, Israel

S. Balter

Columbia University Medical Center, New York, NY, USA

R. Dixon

Department of Radiology, University of North Carolina,

Chapel Hill, NC, USA
}

\section{Methodology}

CIRSE and SIR produce their safety-related documents using the following process. The CIRSE Standards of Practice and SIR Safety and Health Committee members conceptualize documents of relevance and timeliness. A recognized expert is identified to serve as the principal author for the document. Additional authors may be assigned, dependent on the magnitude of the project.

An in-depth literature search is performed using electronic medical literature databases. As appropriate, a critical review of peer-reviewed articles and regulatory documents is performed with regard to the study methodology, results, and conclusions. The qualitative weight of these articles is evaluated and used to write the document such that it contains evidence-based data, when available. Agreement was reached on all statements in this document without the need for utilizing modified Delphi consensus techniques.

\author{
R. Padovani \\ Azienda Ospedaliero-Universitaria S. Maria della Misericordia, \\ SOC di Emodinamica Piazzale S. Maria della Misericordia, \\ Udine, Italy \\ B. Schueler \\ Department of Radiology, Mayo Clinic, Rochester, MN, USA \\ J. F. Cardella \\ Department of Radiology, Geisinger Health System, Danville, \\ PA, USA \\ T. de Baère \\ Department of Interventional Radiology, \\ Institut Gustave-Roussy, Villejuif, France
}


The draft document is critically reviewed by the CIRSE Standards of Practice committee and separately by the SIR Safety and Health Committee, by either telephone, conference calling, or face-to-face meeting. Prior to its publication, the CIRSE Executive Committee and the SIR Executive Council endorse the document.

\section{Introduction}

Fluoroscopically guided interventional procedures are performed in large numbers in Europe and in the United States. The number of procedures performed annually throughout the world has increased over the past 20 years [1]. The benefits of interventional radiology to patients are both extensive and beyond dispute, but many of these procedures also have the potential to produce patient radiation doses high enough to cause radiation effects and occupational doses to interventional radiologists high enough to cause concern [1-4]. A joint SIR-CIRSE guideline on patient radiation management has addressed patient issues [3]. This guideline is intended to serve as a companion to that document and provides guidance to help minimize occupational radiation dose.

The radiation dose received by interventional radiologists can vary by more than an order of magnitude for the same type of procedure and for similar patient dose [4]. Recently, there has been particular concern regarding occupational dose to the lens of the eye in interventional radiologists [2]. New data from exposed human populations suggest that lens opacities (cataracts) occur at doses far lower than those previously believed to cause cataracts $[5,6]$. Statistical analysis of the available data suggests absence of a threshold dose, although if one does exist, it is possible that it is less than 0.1 Gy [7, 8]. Additionally, it appears that the latency period for radiation cataract formation is inversely related to the radiation dose [5].

Occupational radiation protection is a necessity whenever radiation is used in the practice of medicine. It is especially important for image-guided medical procedures $[4,9]$. These procedures may involve high radiation dose rates in the interventional laboratory [10, 11]. Occupational radiation protection is necessary, not only during fluoroscopically guided procedures but also during CT-guided procedures, including CT fluoroscopy. CT fluoroscopy is not really fluoroscopy at all. It differs from conventional fluoroscopy in both equipment and technique. The radiation protection concerns for CT fluoroscopy differ somewhat, particularly in terms of avoiding an excessive radiation dose to the interventional radiologist's hands [12, 13].

Occupational radiation protection requires both the appropriate education and training for the interventional radiologist and the availability of appropriate protection tools and equipment. Occupational radiation protection measures must also comply with local and national regulations, and should also consider the ergonomic detriment caused by personal protective devices [14-16].

Occupational radiation protection measures are necessary for all individuals who work in the interventional fluoroscopy suite. This includes not only technologists and nurses, who spend a substantial amount of time in a radiation environment, but also individuals such as anesthesiologists who may be in a radiation environment only occasionally. All of these individuals may be considered radiation workers, depending on their level of exposure and on national regulations. All workers require appropriate monitoring, as well as protection tools and equipment. They must also receive education and training appropriate to their jobs [14]. The level of training should be based on the level of risk.

This guideline is intended to offer a basic review of the medical physics relevant to occupational radiation safety and to provide advice and guidance to interventional radiologists who perform procedures with the guidance of ionizing radiation and their staff. In this document, the emphasis is radiation protection during fluoroscopically guided procedures.

\section{Measurement of Occupational Exposure}

\section{Quantities and Units}

International organizations have published recommendations on the quantities and units that should be used in occupational dosimetry [15, 17]. National regulations provide specific requirements for personal dosimetry in interventional practice. Dose limits to workers are expressed in terms of equivalent dose in an organ or tissue $\left(\mathrm{H}_{\mathrm{T}}\right)$ for exposure of part of the body and effective dose $(\mathrm{E})$ for whole-body exposure. The SI unit for both quantities is the sievert (Sv).

Equivalent dose and effective dose cannot be measured directly. They must be calculated from other, simpler quantities that can be measured with personal dosimeters. Equivalent dose is the mean absorbed dose in a tissue or organ, $\mathrm{T}$, multiplied by a radiation weighting factor, $\mathrm{w}_{\mathrm{R}}$. For diagnostic X-rays, $w_{R}=1$, so the absorbed dose and the equivalent dose are numerically equal. Effective dose is the weighted sum of the equivalent doses in all specified tissues and organs of the body. These tissue weighting factors, $\mathrm{w}_{\mathrm{T}}$, are highest for red bone marrow, breast, colon, lung, and stomach and lowest for cortical bone, salivary glands, brain, and skin [15]. 
A typical personal dosimeter provides two values, $\mathrm{Hp}(0.07)$ and $\mathrm{Hp}(10)$. These represent the dose equivalent in soft tissue at 0.07 and $10 \mathrm{~mm}$ below the surface of the body, respectively, at the location of the dosimeter [15]. $\mathrm{Hp}(0.07)$ from the collar dosimeter worn over protective garments (apron, thyroid shield) provides a reasonable estimate of the dose delivered to the surface of the unshielded skin and to the lens of the eye. Consultation with a qualified medical physicist is recommended if the collar dosimeter is used to estimate dose to the lens of the eye. In Europe, $\mathrm{Hp}(10)$ from the dosimeter worn on the anterior chest inside protective garments is assumed to be a good estimate of the operator's effective dose and was previously considered an adequate indicator of the health detriment from radiation exposure. A single under-lead dosimeter does not provide any information about eye dose.

The formula used to estimate $\mathrm{E}$ from dosimeter data may be specified by national regulations or by local hospital policy. In the United States when a protective apron is worn during diagnostic and interventional medical procedures using fluoroscopy, the National Council on Radiation Protection and Measurements (NCRP) recommends combining the $\mathrm{Hp}(10)$ values from both body and collar dosimeters to estimate effective dose:

$\mathrm{E}($ estimate $)=0.5 \mathrm{H}_{\mathrm{W}}+0.025 \mathrm{H}_{\mathrm{N}}$,

where $\mathrm{H}_{\mathrm{N}}$ is the reading from the dosimeter at the neck, outside the protective apron, and $\mathrm{H}_{\mathrm{W}}$ is the reading from the dosimeter at the waist or on the chest, under the protective apron [16].

\section{Uncertainties in Occupational Dosimetry}

All formulas used to estimate $\mathrm{E}$ from dosimeter readings are based on certain assumptions about the wearer's radiation protective garments. For safety reasons, most of the commonly used formulas overestimate the individual's actual effective dose. The various formulas, and their associated inaccuracies, are discussed in NCRP Report 122 [16]. The formula given above is unlikely to underestimate E by more than a few percent or overestimate it by more than $100 \%$ [16].

Personal dosimeters in the interventional laboratory are exposed to a radiation field composed of both X-rays that irradiate the dosimeter directly and X-rays reflected or scattered back from the wearer's body. Accuracy and precision are affected by factors that influence the amount of radiation reaching the dosimeter from these two sources compared to the calibration conditions. Additional uncertainties arise because of the differences between monitor calibration conditions and the radiation environment in an interventional laboratory. The NCRP has published a full report on dosimetric uncertainty [18].

Inaccurate dosimetry results arise from mistakes or omissions made by those involved in the overall logistical chain of events of the monitoring program. These include wearing the dosimeter inappropriately or in the wrong location on the body and leaving the dosimeter in a radiation environment. Individuals may also forget to wear or purposely not wear their dosimeter. These actions result in an incorrect value for $\mathrm{E}$ and make it impossible to determine the user's true occupational risk [18].

\section{Occupational Dosimetry in the Interventional Laboratory}

\section{Dosimeter Use}

Radiation workers are monitored to determine their level of exposure. To allow adequate time for identification of practices leading to high personal dose and implementation of work habit changes, monthly monitor replacement is recommended for operators conducting interventional procedures. In some jurisdictions, monthly monitor replacement is mandatory.

Several international and national organizations have published recommendations on occupational dosimetry that are applicable to workers in interventional laboratories. The relatively high occupational exposures in interventional radiology require the use of robust monitoring arrangements for staff. The International Commission on Radiological Protection (ICRP) recommends that interventional radiology departments develop a policy that staff wear two dosimeters, one under the apron and one at collar level above the lead apron [10]. Hand doses may also be monitored, using an additional dosimeter [19].

For pregnant workers, fetal dose is usually estimated using a dosimeter placed on the mother's abdomen, under her radiation protective garments. This dosimeter overestimates actual fetal dose because radiation attenuation by the mother's tissues is not considered.

\section{Dose Limits}

Dose limits for occupational exposures are expressed in equivalent doses for deterministic effects in specific tissues and as the effective dose for stochastic effects throughout the body.

The occupational dose limits recommended by the ICRP have been adopted by most of the countries in the world, including the European Union and the United States [15]. The limits are described slightly differently in the European Union and the United States. In the European Union, 
the limit for effective dose is $20 \mathrm{mSv}$ per year, averaged over defined periods of 5 years. The effective dose may not exceed $50 \mathrm{mSv}$ in any 1 year. Individual members of the European Union may set stricter limits. Germany, for example, has established a 400-mSv lifetime dose limit. In the United States, individual state governments set occupational dose limits, but in most cases the recommendations developed by the NCRP are used [20]. These recommendations include an occupational limit of $50 \mathrm{mSv}$ in any 1 year and a lifetime limit of $10 \mathrm{mSv}$ multiplied by the individual's age in years. While the European Union and U.S. recommendations are not identical, they result in very similar outcomes.

Additional restrictions apply to the occupational exposure of pregnant women. For women who may be pregnant, the ICRP recommends that the standard of protection for the conceptus should be broadly comparable to that provided for members of the general public [15]. After a worker has declared her pregnancy, her working conditions should ensure that the additional dose to the embryo/fetus does not exceed about $1 \mathrm{mSv}$ during the remainder of the pregnancy. In the United States, the NCRP recommends a $0.5-\mathrm{mSv}$ equivalent dose monthly limit for the embryofetus (excluding medical and natural background radiation) once the pregnancy is declared [20]. In the United States, workers who do not wish to declare their pregnancy are not required to do so.

Compliance is demonstrated using a dosimeter worn by the worker at waist level, inside all radiation protective garments, from the date the pregnancy is declared until delivery. The dosimeter must be evaluated monthly. Electronic dosimeters can be used to provide rapid access to data [21]. At those centers where two-dosimeter worker monitoring systems are used, workers who may become pregnant should wear their 'inside' monitor at waist level. Data from these 'inside' monitors provide an estimate of fetal dose from conception to declaration. Workers whose 'inside' badges show an average dose of $<0.1 \mathrm{mSv} /$ month are automatically in compliance with ICRP and NCRP recommendations.

The current limit for the annual equivalent dose to the lens of the eye is $150 \mathrm{mSv}$. This limit is under review by an ICRP Task Group, as there is evidence that it is too high [3, $6,7]$. The annual limit for the hands and feet is $500 \mathrm{mSv}$. The dose received by specific tissues such as the lens of the eye can be estimated by placing a dosimeter on or near the tissue of interest. The 'collar' badge is commonly used to estimate eye dose in interventional laboratories. This method is usually acceptable if the X-ray tube is mounted below the patient. It is not possible to accurately estimate an operator's hand dose using a body or wrist dosimeter because of the proximity of the hands to the X-ray beam. A ring badge is recommended to estimate hand dose [19].

\section{Risk Estimates}

Effective dose (E) is intended to be proportional to the risk of radiation-induced cancer. The ICRP and NCRP occupational limits and limits for the general public are stated in terms of effective dose. (The ICRP refers to these values as dose limits; the NCRP refers to them as maximum permissible dose [MPD].) Regulatory authorities require that a radiation worker receive a radiation dose no higher than the dose limit or MPD. Interventional radiologists are unavoidably irradiated in the performance of their duties. However, a busy interventional radiologist who takes all appropriate radiation safety precautions is unlikely to have an E exceeding $10 \mathrm{mSv} / \mathrm{year}$ and is more likely to have an E of 2-4 mSv/year [22-25]. These values are well below the European dose limits and U.S. MPD. The risk to specific organs such as the fingers or the lens of the eye is related to the physical dose delivered to these tissues.

\section{Evaluation of Personal Dosimetry Data}

\section{Personal Dose Records}

The information in a personal dose record will vary depending on the number, type, and location of personal dosimeters used. This record will contain information on the effective dose E, assessed from the readings of one or two dosimeters worn on the chest or abdomen under and/or over the lead apron, and may contain information on the equivalent dose to the lens of the eye from the dosimeter worn at the collar level over the apron or thyroid collar and the equivalent dose to the hand from a ring or bracelet dosimeter.

Copies of these dose reports should be sent to each department and individual at least every year. The relevant information contained in the dosimetry report to an individual includes the doses for the current period and the current year.

\section{Surveillance of Occupational Dose}

The facility's Radiation Safety section or Medical Physics Service should review the personal dose records of individual workers regularly. This review ensures that dose limits are not exceeded. It also evaluates whether the dose received is at the level expected for that worker's particular duties. Workers' recorded dose levels should be compared to their own past dose levels and to the average dose levels of others doing similar work at the same facility or at other facilities. Typical staff dose readings for different types of procedures have been published in the literature $[11,19,26-36]$. Depending on the type of procedure and the technique used, 
the operator dose, per procedure, ranges from 3 to $450 \mu \mathrm{Sv}$ at the neck over protective garments, from $<0.1$ to $32 \mu \mathrm{Sv}$ at the waist or chest under protective garments, and from 48 to $1280 \mu \mathrm{Sv}$ at the hand. Unfortunately, most of the published data are stated in terms of dose per procedure, and most of the data are for physicians rather than assistants, nurses, technologists, or other staff. Translating these data into monthly or annual worker doses is difficult. As noted above, the effective dose for an interventional radiologist is typically 2-4 mSv/year [22-25].

\section{Investigation of High Occupational Dose}

The World Health Organization (WHO) recommends investigation when monthly exposure reaches $0.5 \mathrm{mSv}$ for effective dose, $5 \mathrm{mSv}$ for dose to the lens of the eye, or $15 \mathrm{mSv}$ to the hands or extremities [9]. The Radiation Safety Officer or a qualified medical physicist should contact the worker directly to determine the cause of the unusual dose and to make suggestions about how to keep the worker's dose as low as reasonably achievable (ALARA).

Badge readings for workers in interventional laboratories can be expected to be higher than for most other hospital workers. Most other hospital workers are expected to have minimal occupational radiation exposure. Using the same investigation criteria for both groups leads to nonproductive investigations of interventional radiologists and, often, to their reduced compliance with monitor use. ICRP publication 103 discusses how this situation may be avoided, by considering both the need for optimization of protection and the avoidance of arbitrary operational dose limits: "The use of prescriptive requirements should always be carefully justified. In any event, they should never be regarded as an alternative to the process of optimizing protection. It is not satisfactory to set design or operational limits or targets as an arbitrary fraction of the dose limit, regardless of the particular nature of the plant and the operations" [15].

Investigation of a high personal dose value begins with a check of the validity of the dosimeter reading. Potential sources of invalid dosimeter readings include wearing of designated under- and over-apron dosimeters in the wrong location, wearing of a different worker's dosimeter, and dosimeter storage in a location where it is exposed to radiation. If an invalid reading is suspected, the reading for the individual's next monitoring period should be reviewed to ensure the problem has been corrected.

If the dosimeters have been stored and worn correctly, the worker will be asked if there was a change in work habits that could explain the increase in radiation exposure. Was a new type of procedure initiated during the monitoring period? Were procedure techniques or equipment settings modified? If so, did these new methods require increased patient dose or closer proximity to the patient? Did procedure workload or complexity increase? Sometimes, a temporary cause is found. If this is the case, dose levels should return to usual levels during the next monitoring period, when workload returns to normal, equipment settings are corrected, or there is additional experience with a new procedure or technique. The individual's dose reading for the next monitoring period should be reviewed to confirm that dose levels have returned to the expected range.

If the cause is not thought to be temporary, or if no cause can be identified, the individual's working habits should be observed during a series of representative procedures. The observer could be a qualified medical or health physicist or a physician colleague with knowledge of radiation protection principles and the operation of the specific imaging equipment being used. The observer should pay close attention to equipment settings (particularly those that affect patient dose and dose-area product), the worker's proximity to the patient, and the use of equipment mounted shields and personal protective devices. While individual workers may be able to assess their own working habits, an external observer has a different perspective and can point out otherwise unrecognized practices that result in high exposure levels.

Once the cause(s) of high personal dose levels have been identified, and changes to work practices implemented, it can be helpful for the individual to wear a realtime dosimeter to provide frequent feedback of radiation dose levels. With adequate cooperation and attention to dose reduction principles, forced limitation of workload to ensure compliance with dose limits is generally not needed.

\section{Radiation Protection Tools}

The greatest source of radiation exposure to the operator and staff is scatter from the patient. Generally, controlling patient dose also reduces scatter and limits operator dose. However, chronic radiation exposure in the work place mandates the use of protective tools in order to limit occupational radiation dose to an acceptable level. The purpose of radiation protection tools is to improve operator and staff safety without impeding the procedure or jeopardizing the patient's safety.

\section{Shielding}

There are three types of shielding: architectural shielding, equipment mounted shields, and personal protective devices. Architectural shielding is built into the walls of the 
procedure room. This type of shielding is not discussed further here. In addition, rolling and stationary shields which rest on the floor, constructed of transparent leaded plastic, are available and are useful for providing additional shielding for both operators and staff. They are particularly well suited for use by nurses and anesthesia personnel [37].

Equipment-mounted shielding includes protective drapes suspended from the table and from the ceiling. Table-suspended drapes hang from the side of the patient table, between the under-table X-ray tube and the operator. They should always be employed, as they have been shown to substantially reduce operator dose [38]. Unfortunately, they sometimes cannot be used if the X-ray gantry (C-arm) is in a steep oblique or lateral position.

Ceiling-suspended shields, generally constructed of a transparent leaded plastic, should also be used during cases of any significant length. Properly placed shields have been shown to dramatically reduce operator eye dose [39, 40]. It now appears that the threshold dose for cataract formation can be reached within several years for a moderately busy practitioner, so suspended shields or some other form of eye protection should be used by anyone performing interventional procedures on a regular basis [2]. Lens injuries have been reported in both operators and staff when systems which lack ceiling-suspended shields are used for complex interventional procedures [41].

Disposable, protective patient drapes are now available. These contain metallic elements (bismuth or tungstenantimony) and are placed on the patient after the operative site has been prepared and draped [42, 43]. They have been shown to reduce operator dose substantially, with reported reductions of 12-fold for the eyes, 26-fold for the thyroid, and 29-fold for the hands [43]. While their use adds some cost to the procedure, disposable protective drapes should be considered for complex procedures and procedures where the operator's hands must be near the radiation field (e.g., management of dialysis fistulas and grafts, biliary and genitourinary interventions) [43].

\section{Personal Protective Devices}

Personal protective devices include aprons, thyroid shields, eyewear, and gloves. Protective aprons with thyroid shields are the principal radiation protection tool for interventional workers. They should be employed at all times. The vest/ skirt configuration is preferred by many operators in order to reduce the risk of musculoskeletal/back injury [44]. This wrap-around style is typically $0.25 \mathrm{~mm}$ lead-equivalent so that, when worn, the double thickness anteriorly provides 0.5 -mm lead-equivalence. Operators and staff who work in the interventional laboratory on a regular basis should be provided with properly fitted aprons, both to reduce ergonomic hazards and to provide optimal radiation protection
[45]. Aprons should be inspected fluoroscopically on an annual basis to detect deterioration and defects in the protective material [46].

Because of the ergonomic hazards of personal protective devices (particularly leaded aprons), attempts to reduce the fatigue and injury associated with wearing heavy protective apparel have been made [44]. An early version of a "weightless apron" involved a rolling device from which the apron was hung. This was positioned behind the operator and rolled as the interventional radiologist moved [47]. A newer iteration, recently introduced, travels on a set of ceiling mounted rails and is easily donned within seconds [48]. This newer device extends from the head to the distal portions of the lower extremities and provides substantial protection to the wearer. Devices such as these hold promise for improved ergonomics and safety. As new protective devices become available, they should be evaluated critically and adopted if shown to improve radiation protection and reduce ergonomic hazards.

Since the current ICRP occupational limit for eye exposure of $150 \mathrm{mSv} / \mathrm{year}$ may be too high, and since radiation cataract formation may be a stochastic effect, operators are strongly advised to use eye protection at all times $[2,15]$. Leaded eyeglasses are an alternative to ceiling-suspended shields for this purpose. Leaded eyeglasses with large lenses and protective side shields provide more protection than eyeglasses without these features. They help to minimize scatter which approaches the operator from the side and scatter from the operator's own head [49]. The principal disadvantage of leaded eyeglasses is their weight and discomfort.

In general, the operator's hands should be kept out of the primary radiation beam. Leaded gloves may seem useful for radiation protection on those rare occasions when the operator's hands must be in the primary radiation beam, but they do not provide protection in this situation. Because of the increased dose when any shielding is placed in the primary beam, and the false sense of security that these gloves provide, protective gloves can result in increased radiation dose to the hand when the gloved hand is in the primary beam [50]. Leaded gloves are not recommended in this situation. The best way to protect the operator's hands is to keep them out of the radiation field. Leaded gloves may be of benefit if the operator's hands will be near, but not in, the primary radiation beam.

\section{Effectiveness of Shielding}

The shielding material for protective aprons has evolved from heavy, lead-impregnated vinyl or rubber, with a shielding equivalent of $1 \mathrm{~mm}$ of lead, to lighter, composite (lead plus other high-atomic-numbered elements) or entirely lead-free materials. These lighter materials have 
largely replaced the all-lead aprons of the past and typically are designed to provide $0.5-\mathrm{mm}$ lead-equivalent protection anteriorly [51]. Transmission of $70-$ to $100-\mathrm{kVp}$ $\mathrm{X}$-rays through $0.5-\mathrm{mm}$ lead is approximately $0.5 \%-5 \%$ $[22,46]$. The protection provided by $0.5-\mathrm{mm}$ lead-equivalent composite and lead-free aprons has been found to vary, ranging from $0.6 \%$ to $6.8 \%$ transmission [46].

Leaded glasses reduce the dose to the operator's eye from frontal exposure by a factor of approximately 8-10 [40, 52]. When side exposure is included (the typical situation in clinical practice), the protection factor is decreased to between 2 and 3 [53]. Combining various types of shielding (i.e., table-suspended drapes, ceiling-suspended screens, aprons, leaded glasses, mobile shields, and disposable drapes) results in a dramatic dose reduction for the operator $[37,40]$. This should be the norm, rather than the exception.

\section{Scatter}

Detailed discussion of scatter isodose curves is beyond the scope of this document. Readers are directed to the extensive work in the literature [2,54-56]. The magnitude and distribution of scattered radiation are affected by many factors, including patient size, gantry angulation, patient position, filtration, fluoroscopic settings, and the use of shielding. Overall, in an unshielded environment, and for a posteroanterior (PA) projection, the exposure is greatest below the table, less at the operator's waist level, and least at the eye level. However, substantial operator eye doses can be reached in unfavorable circumstances (large patient, high-dose fluoroscopy/fluorography, gantry angulation), underscoring the importance of proper protection, particularly for the eyes $[54,57]$.

\section{Practical Advice to Reduce or Minimize the Occupational Radiation Dose}

Decreasing patient dose will result in a proportional decrease in scatter dose to the operator. Therefore, techniques that reduce patient dose will generally also reduce your occupational dose. This is a "win-win" situation; you and your patient both benefit. (Of course, the greatest reduction occurs when imaging is performed without ionizing radiation, such as with ultrasound.) Additional techniques can be used with fluoroscopically guided procedures to reduce occupational dose. Both types of techniques are listed in Table 1 and described in more detail below.

\section{Minimize Fluoroscopy Time}

Fluoroscopy should be used only to observe objects or structures in motion. Review the last-image-hold for study,
Table 1 Key points for safe practice

- Minimize fluoroscopy time.

- Minimize the number of fluorographic images.

- Use available patient dose reduction technologies.

- Use good imaging-chain geometry.

- Use collimation.

- Use all available information to plan the interventional procedure.

- Position yourself in a low-scatter area.

- Use protective shielding.

- Use appropriate fluoroscopic imaging equipment.

- Obtain appropriate training.

- Wear your dosimeters and know your own dose!

Note: See text for details

consultation, or education instead of additional fluoroscopic exposure. If available, use fluoroscopy loop recording to review dynamic processes. Use short taps of fluoroscopy instead of continuous operation. Fluoroscopy to determine or adjust collimator blade positioning can be eliminated by using the virtual collimation feature, when present.

Minimize the Number of Fluorographic Images

For digital subtraction angiography, use variable frame rates tailored to the examination (e.g., 1 image/s for $6 \mathrm{~s}$, then 1 image every other second for $24 \mathrm{~s}$, for arteriography of the celiac axis) instead of a constant frame rate (e.g., 2 images/s for $30 \mathrm{~s}$ ). Suggested imaging sequences are available in some older standard textbooks $[58,59]$. For documentation, use stored last-image-hold images instead of acquiring additional images. When available, use a stored fluoroscopy loop instead of a fluorographic acquisition, if the image quality is adequate to document the findings.

\section{Use Available Patient Dose Reduction Technologies}

These include low-fluoroscopy-dose-rate settings, lowframe-rate pulsed fluoroscopy, removal of the antiscatter grid, spectral beam filtration, and use of increased X-ray beam energy. Improved image processing within the fluoroscopic unit can compensate to a considerable degree for the reduced image quality due to decreased exposure levels. Catheters with highly radiopaque tips are easier to see. Children and some small adults can be imaged without the antiscatter grid. This technique reduces dose at the cost of somewhat decreased image quality.

\section{Use Good Imaging-Chain Geometry}

Position the patient support so that the patient is as far as possible from the X-ray tube. Place the image receptor as close as possible to the patient. 


\section{Use Collimation}

Adjust collimator blades tightly to the area of interest. Tight collimation reduces patient dose and improves image quality by reducing scatter. When beginning a case, position the $\mathrm{C}$-arm over the area of interest, with the collimators almost closed. Open the collimators gradually until the desired field of view is obtained.

Use All Available Information to Plan the Interventional Procedure

When appropriate, use pre-procedure imaging (ultrasound, MRI, CT) to define the relevant anatomy and pathology and to plan the interventional procedure.

\section{Position Yourself in a Low-Scatter Area}

Stay as far away from the X-ray beam as possible. (Remember the inverse square law!) Use tubing extensions or needle holders so that your hands are away from the exposed field. Never place your hands in the X-ray beam. Use power injectors for contrast material injections when feasible, and step out of the procedure room during fluorographic acquisitions (digital subtraction angiography). When using angulated or lateral projections, keep in mind that the highest intensity of scattered radiation is located on the X-ray beam entrance side of the patient. When using these projections, the X-ray tube should be on the side opposite the operator whenever possible. Avoid using equipment with over-the-table X-ray tubes for interventional procedures.

\section{Use Protective Shielding}

When you perform fluoroscopically guided interventions, you should wear a personal protective apron and a thyroid shield. Ceiling-suspended shields can provide significant additional dose reduction, especially to unprotected areas of your head and neck. Leaded eyewear is recommended if ceiling-suspended shields cannot be used continuously during the entire procedure. Under-table lead drapes reduce lower extremity dose substantially and should be used whenever possible.

\section{Use Appropriate Fluoroscopic Imaging Equipment}

Imaging systems optimized for one type of procedure or body part may be suboptimal for others. Using fluoroscopy equipment under suboptimal conditions frequently results in increased radiation dose. Furthermore, high-radiationdose procedures should be performed with fluoroscopic systems that incorporate recommended dose-reduction technology and comply with the most current International Electrotechnical Commission standards [60]. Encourage your institution to purchase this kind of equipment for interventional laboratories.

\section{Obtain Appropriate Training}

The International Atomic Energy Agency has produced a free training program, which can be downloaded at http://rpop. iaea.org/RPOP/RPoP/Content/-AdditionalResources/Training/ 1_TrainingMaterial/Radiology.htm. The MARTIR project (Multimedia and Audiovisual Radiation Protection Training in Interventional Radiology) also produced a free training program, originally distributed on $\mathrm{CD}-\mathrm{ROM}$, that is now available on the Internet (Windows only), at http:// ec.europa.eu/energy/wcm/nuclear/cd_rom_martir_project.zip. The MARTIR training program is older but has several nice videos, many slides, and a good self-evaluation tool (very useful for residents and fellows).

You and all staff involved in the procedure should have a general knowledge of safe operating practices in a radiation environment. You should be thoroughly familiar with the operation of the particular fluoroscopy equipment you are using. If appropriate medical simulators are available, you should consider using them to learn and practice new skills before you apply them to patients.

Wear Your Dosimeters and Know Your Own Dose!

You need to know your occupational dose in order to ensure that you are working safely. Your dose data will not be accurate unless you always wear your dosimeters, and wear them correctly.

\section{Management Responsibilities}

Management should provide an appropriate level of resources, such as staff, facilities, and equipment, to ensure that radiation dose is adequately controlled. Facilities and equipment include, but are not limited to, shielding, radiation monitoring instruments, and protective clothing. Quality assurance is an essential component of any monitoring program [61]. Occupational doses should be analyzed by each department; high doses and outliers should be investigated.

Protective aprons should be examined fluoroscopically every year and inspected visually on a daily or weekly basis for damage and defects [46]. Standardized methods for acceptance testing of protective aprons are needed, due to the wide variation in actual attenuation values of aprons $[46,51]$. 
Adequate and relevant training programs should be provided for all levels of staff within the organization, including management, to develop a commitment to radiological protection and in order that all concerned can contribute to the reduction and control of exposures [61].

\section{References}

1. Miller DL (2008) Overview of contemporary interventional fluoroscopy procedures. Health Phys 95:638-644

2. Vano E, Gonzalez L, Fernández JM, Haskal ZJ (2008) Eye lens exposure to radiation in interventional suites: caution is warranted. Radiology 248:945-953

3. Stecker MS, Balter S, Towbin RB et al (2009) Guidelines for patient radiation dose management. J Vasc Interv Radiol 20: S263-S273

4. Kim KP, Miller DL, Balter S et al (2008) Occupational radiation doses to operators performing cardiac catheterization procedures. Health Phys 94:211-227

5. Kleiman NJ (2007) Radiation cataract. In: Working party on research implications on health and safety standards of the article 31 group of experts. Radiation Protection 145 EU Scientific Seminar 2006. New insights in radiation risk and basic safety standards. European Commission, Brussels, pp 81-95. Available at: http:// ec.europa.eu/energy/nuclear/radioprotection/publication/doc/145 en.pdf. Accessed August 16, 2009

6. Worgul BV, Kundiyev YI, Sergiyenko NM et al (2007) Cataracts among Chernobyl clean-up workers: implications regarding permissible eye exposures. Radiat Res 167:233-243

7. Nakashima E, Neriishi K, Minamoto A (2006) A reanalysis of atomic-bomb cataract data, 2000-2002: a threshold analysis. Health Phys 90:154-160

8. Neriishi K, Nakashima E, Minamoto A et al (2007) Postoperative cataract cases among atomic bomb survivors: radiation dose response and threshold. Radiat Res 168:404-408

9. World Health Organization (2000) Efficacy and radiation safety in interventional radiology. World Health Organization, Geneva

10. International Commission on Radiological Protection (2000) Avoidance of radiation injuries from medical interventional procedures. ICRP Publication 85. Ann ICRP 30:7-67

11. Vañó E, González L, Guibelalde E, Fernández JM, Ten JI (1998) Radiation exposure to medical staff in interventional and cardiac radiology. Br J Radiol 71:954-960

12. Stoeckelhuber BM, Leibecke T, Schulz E et al (2005) Radiation dose to the radiologist's hand during continuous CT fluoroscopyguided interventions. CardioVasc Interv Radiol 28:589-594

13. Hohl C, Suess C, Wildberger JE et al (2008) Dose reduction during CT fluoroscopy: phantom study of angular beam modulation. Radiology 246:519-525

14. European Commission (2000) Radiation protection 116. Guidelines on education and training in radiation protection for medical exposures. Directorate-General for the Environment, European Commission, Luxembourg. Available at: http://ec.europa.eu/energy/nuclear/ radiation_protection/doc/publication/116pdf. Accesed August 16,2009

15. International Commission on Radiological Protection (2007) The 2007 recommendations of the International Commission on Radiological Protection. ICRP Publication 103. Ann ICRP 37:1332

16. National Council on Radiation Protection and Measurements (1995) Use of personal monitors to estimate effective dose equivalent and effective dose to workers for external exposure to
low-LET radiation. NCRP Report No. 122. National Council on Radiation Protection and Measurements, Bethesda, MD

17. International Commission on Radiological Protection (1996) Conversion coefficients for use in radiological protection against external radiation. Adopted by the ICRP and ICRU in September 1995. Ann ICRP 26:1-205

18. National Council on Radiation Protection and Measurements (2008) Uncertainties in the measurement and dosimetry of external radiation: recommendations of the National Council on Radiation Protection and Measurements. NCRP Report No. 158. National Council on Radiation Protection and Measurements, Bethesda, MD

19. Whitby M, Martin CJ (2005) A study of the distribution of dose across the hands of interventional radiologists and cardiologists. Br J Radiol 78:219-229

20. National Council on Radiation Protection and Measurements (1993) Limitation of exposure to ionizing radiation. NCRP Report No. 116. National Council on Radiation Protection and Measurements, Bethesda, MD

21. Balter S, Lamont J (2002) Radiation and the pregnant nurse. Cath Lab Dig 10:e1. Available at: http://www.cathlabdigest.com/ article/357. Accessed August 16, 2009

22. Marx MV, Niklason L, Mauger EA (1992) Occupational radiation exposure to interventional radiologists: a prospective study. J Vasc Interv Radiol 3:597-606

23. Tsapaki V, Kottou S, Vano E et al (2004) Occupational dose constraints in interventional cardiology procedures: the DIMOND approach. Phys Med Biol 49:997-1005

24. Delichas M, Psarrakos K, Molyvda-Athanassopoulou E et al (2003) Radiation exposure to cardiologists performing interventional cardiology procedures. Eur J Radiol 48:268-273

25. Dendy PP (2008) Radiation risks in interventional radiology. Br J Radiol 81:1-7

26. Stratakis J, Damilakis J, Hatzidakis A, Theocharopoulos N, Gourtsoyiannis N (2006) Occupational radiation exposure from fluoroscopically guided percutaneous transhepatic biliary procedures. J Vasc Interv Radiol 17:863-871

27. Layton KF, Kallmes DF, Cloft HJ, Schueler BA, Sturchio GM (2006) Radiation exposure to the primary operator during endovascular surgical neuroradiology procedures. Am J Neuroradiol 27:742-743

28. Stavas JM, Smith TP, DeLong DM, Miller MJ, Suhocki PV, Newman GE (2006) Radiation hand exposure during restoration of flow to the thrombosed dialysis access graft. J Vasc Interv Radiol 17:1611-1617

29. Lipsitz EC, Veith FJ, Ohki T et al (2000) Does the endovascular repair of aortoiliac aneurysms pose a radiation safety hazard to vascular surgeons? J Vasc Surg 32:704-710

30. Buls N, Pages J, Mana F, Osteaux M (2002) Patient and staff exposure during endoscopic retrograde cholangiopancreatography. Br J Radiol 75:435-443

31. Sulieman A, Theodorou K, Vlychou M et al (2008) Radiation dose optimisation and risk estimation to patients and staff during hysterosalpingography. Radiat Prot Dosimetry 128:217-226

32. Hellawell GO, Mutch SJ, Thevendran G, Wells E, Morgan RJ (2005) Radiation exposure and the urologist: what are the risks? J Urol 174:948-952

33. Botwin KP, Thomas S, Gruber RD et al (2002) Radiation exposure of the spinal interventionalist performing fluoroscopically guided lumbar transforaminal epidural steroid injections. Arch Phys Med Rehab 83:697-701

34. Harstall R, Heini PF, Mini RL, Orler R (2005) Radiation exposure to the surgeon during fluoroscopically assisted percutaneous vertebroplasty: a prospective study. Spine 30:1893-1898

35. Kallmes DF, O E, Roy SS et al (2003) Radiation dose to the operator during vertebroplasty: prospective comparison of the use 
of 1-cc syringes versus an injection device. Am J Neuroradiol 24:1257-1260

36. Synowitz M, Kiwit J (2006) Surgeon's radiation exposure during percutaneous vertebroplasty. J Neurosurg Spine 4:106-109

37. Luchs JS, Rosioreanu A, Gregorius D, Venkataramanan N, Koehler V, Ortiz AO (2005) Radiation safety during spine interventions. J Vasc Interv Radiol 16:107-111

38. Shortt CP, Al-Hashimi H, Malone L, Lee MJ (2007) Staff radiation doses to the lower extremities in interventional radiology. CardioVasc Interv Radiol 30:1206-1209

39. Maeder M, Brunner-La Rocca HP, Wolber T et al (2006) Impact of a lead glass screen on scatter radiation to eyes and hands in interventional cardiologists. Cath Cardiovasc Interv 67:18-23

40. Thornton RH, Altamirano J, Dauer L (2009) Comparing strategies for IR eye protection. J Vasc Interv Radiol 20:S52-S53; abstract

41. Vañó E, González L, Beneytez F, Moreno F (1998) Lens injuries induced by occupational exposure in non-optimized interventional radiology laboratories. Br J Radiol 71:728-733

42. Dromi S, Wood BJ, Oberoi J, Neeman Z (2006) Heavy metal pad shielding during fluoroscopic interventions. J Vasc Interv Radiol 17:1201-1206

43. King JN, Champlin AM, Kelsey CA, Tripp DA (2002) Using a sterile disposable protective surgical drape for reduction of radiation exposure to interventionalists. Am $\mathrm{J}$ Roentgenol 178:153-157

44. Klein LW, Miller DL, Balter S et al (2009) Occupational health hazards in the interventional laboratory: time for a safer environment. J Vasc Interv Radiol 20:147-152 quiz 153

45. Detorie N, Mahesh M, Schueler BA (2007) Reducing occupational exposure from fluoroscopy. J Am Coll Radiol 4:335-337

46. Christodoulou EG, Goodsitt MM, Larson SC, Darner KL, Satti J, Chan HP (2003) Evaluation of the transmitted exposure through lead equivalent aprons used in a radiology department, including the contribution from backscatter. Med Phys 30:1033-1038

47. Pelz DM (2000) Low back pain, lead aprons, and the angiographer. Am J Neuroradiol 21:1364

48. Savage C, Carlson L, Clements J, Rees C (2009) Comparison of the Zero Gravity system to conventional lead apron for radiation protection of the interventionalist. J Vasc Interv Radiol 20:S53
49. Cousin AJ, Lawdahl RB, Chakraborty DP, Koehler RE (1987) The case for radioprotective eyewear/facewear. Practical implications and suggestions. Invest Radiol 22:688-692

50. Wagner LK, Mulhern OR (1996) Radiation-attenuating surgical gloves: effects of scatter and secondary electron production. Radiology 200:45-48

51. Finnerty M, Brennan PC (2005) Protective aprons in imaging departments: manufacturer stated lead equivalence values require validation. Eur Radiol 15:1477-1484

52. Marshall NW, Faulkner K, Clarke P (1992) An investigation into the effect of protective devices on the dose to radiosensitive organs in the head and neck. Br J Radiol 65:799-802

53. Moore WE, Ferguson G, Rohrmann C (1980) Physical factors determining the utility of radiation safety glasses. Med Phys 7:8 12

54. Balter S (1999) Radiation safety in the cardiac catheterization laboratory: basic principles. Cath Cardiovasc Interv 47:229-236

55. Whitby M, Martin CJ (2003) Radiation doses to the legs of radiologists performing interventional procedures: Are they a cause for concern? Br J Radiol 76:321-327

56. Schueler BA, Vrieze TJ, Bjarnason H, Stanson AW (2006) An investigation of operator exposure in interventional radiology. Radiographics 26:1533-1541

57. Balter S, Sones FM, Brancato R (1978) Radiation exposure to the operator performing cardiac angiography with U-arm systems. Circulation 58:925-932

58. Kandarpa K, Aruny JE (2002) Handbook of interventional radiologic procedures, 3rd edn. Lippincott Williams \& Wilkins, Philadelphia

59. Bakal CW (2002) Vascular and interventional radiology: principles and practice. Thieme, New York

60. International Electrotechnical Commission (2000) Report 60601. Medical electrical equipment-Part 2-43: particular requirements for the safety of X-ray equipment for interventional procedures. International Elelctrotechnical Commission, Geneva, Switzerland

61. International Commission on Radiological Protection (1997) General principles for the radiation protection of workers. ICRP Publication 75. Ann ICRP 27:1-60 